\title{
Does Interface Design Influence Catalog Use? A Case Study
}

\section{Jennifer E. Knievel, Jina Choi Wakimoto, and Sara Holladay}

\begin{abstract}
A recent OPAC redesign and implementation of a link resolver at the University of Colorado at Boulder prompted the researchers to question whether the redesign influenced catalog use. Authors evaluated transactional log data between fall of 2005 and spring of 2008. Searches for keyword, title, author, subject, LC call number, and ISSN/ISBN were tracked for each semester during weeks two and three of the semester, a mid-semester sampling period, and finals week. The data show that keyword searches increased slightly following the redesign, and ISSN/ ISBN searches increased dramatically following implementation of the link resolver. Total searches held steady over the course of the study.
\end{abstract}

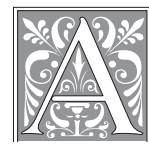

$\mathrm{t}$ the University of Colorado at Boulder, the interface to the Web-based online public access catalog (OPAC) had not been significantly redesigned since its initial debut in 1997. In the fall of 2006 and spring of 2007, a committee undertook the project of completely restructuring the interface. The design for the new interface was based on examples from other research libraries, literature on Web site usage and design, and informal usability testing. This sparked an interest in whether the changes significantly influenced the way that users approached and used the catalog. This study focuses on a quantitative assessment of user search choice as tracked by OPAC transaction logs over three years, both before and after the new interface debuted. During the same period, the library implemented other new discovery tools, whose influence on OPAC use will also be assessed. This study seeks to reveal, to the extent possible with the data available, how users were searching the catalog before the interface redesign, how they search it after the redesign, and what this usage implies about the influence of interface design on catalog use. The authors theorized that the interface redesign would trigger an increase in keyword searches, since the new interface defaulted to keyword search. We also expected a rise in ISSN searches after the implementation of an OpenURL link resolver. Furthermore, there has been a great deal of discussion about the continued relevance of library catalogs in an environment where users are so comfortable with popular search engines. This

Jennifer E. Knievel is Faculty Director of Research and Instruction, Associate Professor, at the University of Colorado at Boulder; e-mail: jennifer.knievel@colorado.edu. Jina Choi Wakimoto is Faculty Director of Cataloging and Metadata Services, Associate Professor, at the University of Colorado at Boulder; e-mail: jina.wakimoto@colorado.edu. Sara Holladay is Electronic Collections and Assessment Librarian, Assistant Professor, at the University of Colorado at Boulder; e-mail: sara.holladay@colorado.edu. 
study seeks to reveal whether a steady decline in usage can be demonstrated by catalog transactional data, in an effort to inform the debate over whether users are beginning to eschew their local library catalogs for wider Internet search engines. User behavior necessarily needs to be evaluated in multiple ways. Qualitative studies of user experience are necessary and are planned for the future, but they are beyond the scope of this project.

\section{Literature Review}

There are different methods of assessing the usefulness of OPACs before and after the implementation of any particular change. In their 1997 article analyzing studies of OPACs since 1990, Large and Beheshti examine five data collection methods: experiment, interview and questionnaire, observation, think aloud, and transaction log. ${ }^{1}$ Each method has its pros and cons. Researchers of online catalogs have widely employed transactional log analysis (TLA) since Meister and Sullivan first utilized it in their research in $1967 .^{2}$ However, TLA has also garnered a fair amount of criticism. In a special issue of Library Hi Tech devoted to a discussion of TLA (1993), many authors note both the merits and limitations of using this method of analysis. Peters gives an excellent overview of the development of TLA, including a review of the first twenty-five years of reported research using transactional log analysis. ${ }^{3}$ Another article in the issue states that continuous review of transaction logs can reveal changes in general user searching styles over the course of time. ${ }^{4}$ Meanwhile, Kurth's article in the issue explores TLA's limitations, particularly its inability to capture a specific user's satisfaction or success with the results of their OPAC search. ${ }^{5}$ Kurth notes that, while using TLA to monitor the patterns of use of individual users is impossible and therefore a major limitation of TLA, there are "tasks for which transaction log analysis is the ideal, if not the only, tool."'6

There exists an abundance of literature on the use of TLA for OPAC studies. ${ }^{7}$
However, these studies mostly examine text-based interfaces. The use of TLA for OPAC studies seems to have fallen out of favor just as libraries began transitioning to Web-based OPACs, which offer many new features and have different characteristics. More recently, Novotny's 2004 research examines the impact of the Internet on user behavior with Web-based OPACs, employing the methodology of protocol analysis (thinking aloud). ${ }^{8} \mathrm{Yu}$ and Young's study investigates the effect of the search engine on subject searching in both text-based and Web-based OPACs. ${ }^{9}$ They report a continuing problem with subject-heading searches and recommend some changes to OPACs.

Researchers from the University of Granada in Spain applied TLA to examine the use of the catalog, with a focus on subject searching. ${ }^{10}$ Understanding that subject searching has been identified as the most problematic search category for users, despite the fact that many libraries offer subject searching as the primary option, they analyzed the log files to determine the most frequent type of search conducted by users. Their results show a strong preference for known item searches, first by title, followed by author, then by subject. Their findings support those of earlier similar studies done using TLA by Hancock-Beaulieu and by Willdemuth and $\mathrm{O}^{\prime}$ Neill. ${ }^{11}$

Another recent study used a combination of transaction logs and system implanted questionnaires to analyze data using multivariate statistical analysis. ${ }^{12}$ Transactional log data captured all activities from the moment a user entered the system to the point of logoff or disconnection. Their findings report that all users clearly prefer known-item searches.

As the literature suggests, transactional log analysis has strengths and weaknesses as a research methodology; it is not an appropriate data collection method for all researchers, and much of the success of using TLA hinges on one's particular research goals. Transactional log analysis became a popular method 


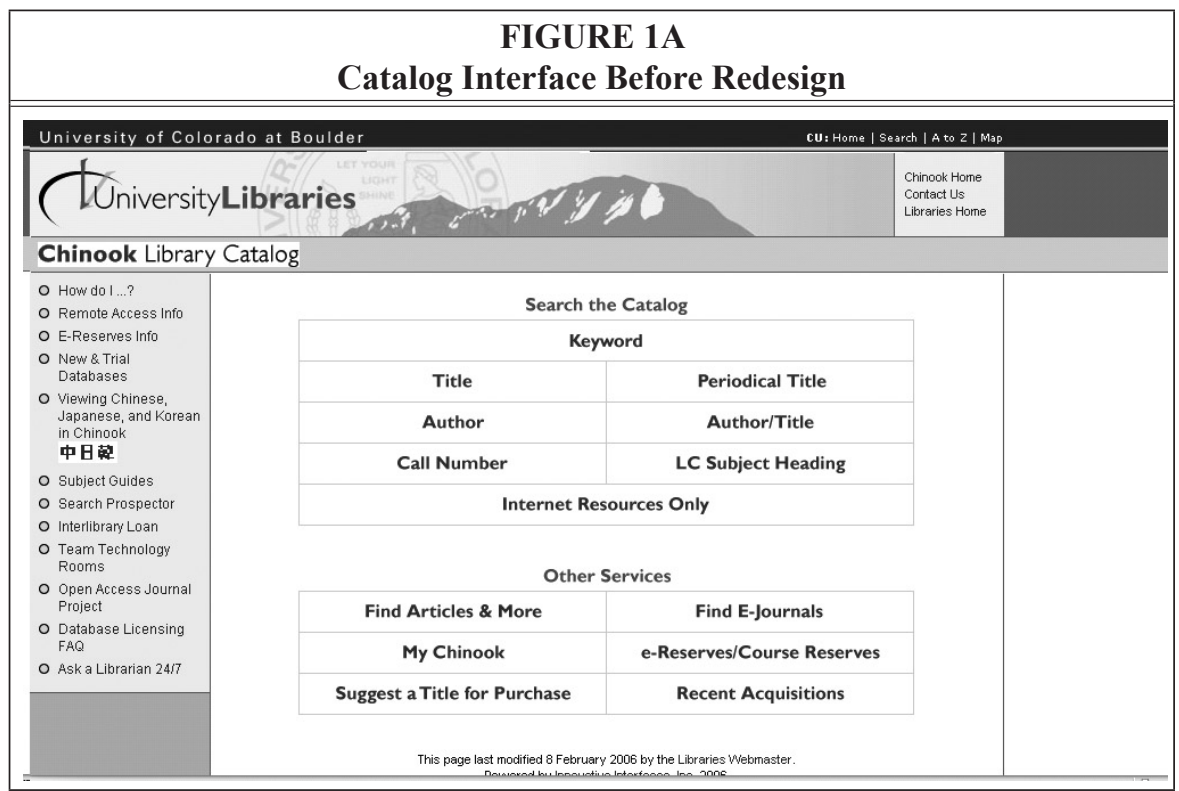

of data collection for OPAC studies due to its strengths: the possibility of capturing large sets of data, unobtrusiveness to users, and unbiased data. However, most of the researchers employing TLA acknowledge its shortcomings as a data collection method: TLA does not take into account individual users' behavior, infor- mation needs or satisfaction; therefore, it only gives a partial picture of the users' information-seeking behavior. Many recommend combining TLA with other data collection methods, such as interviews, video recordings, or questionnaires. ${ }^{13}$ TLA can be most useful when the data are used to improve OPAC interfaces.

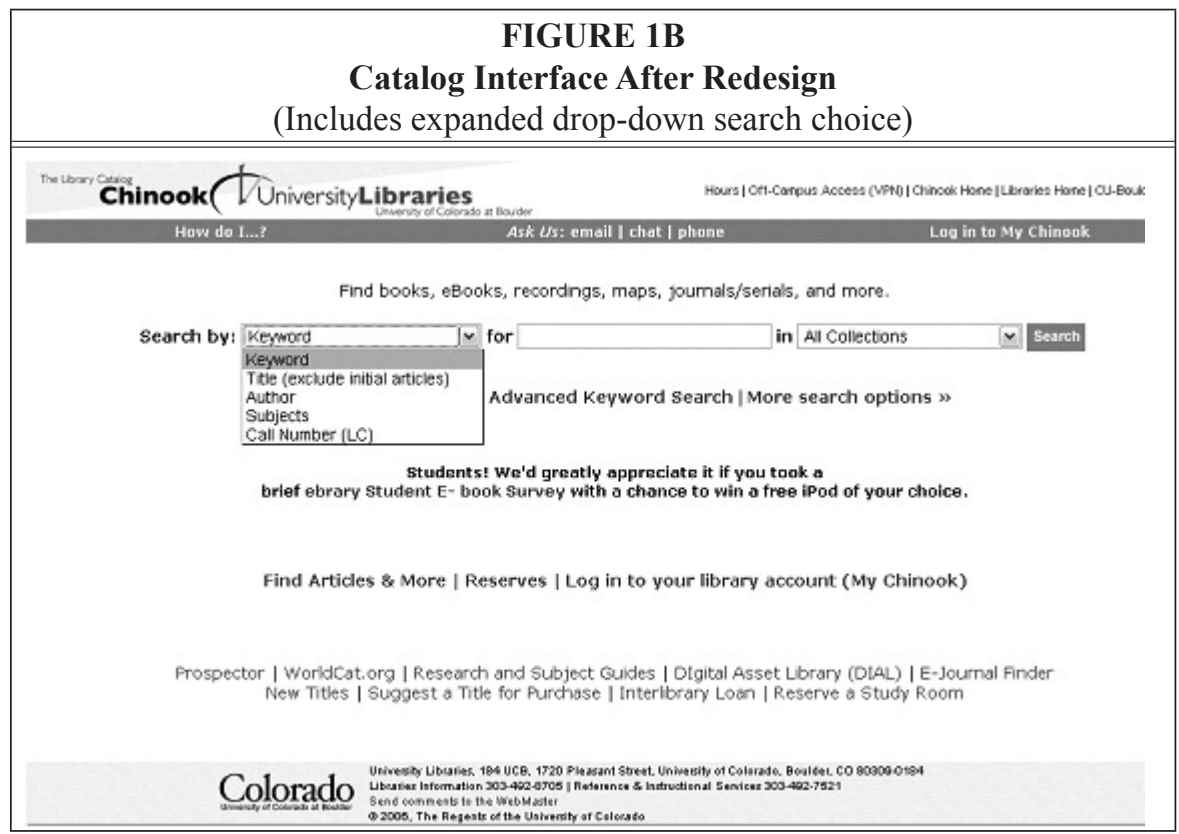




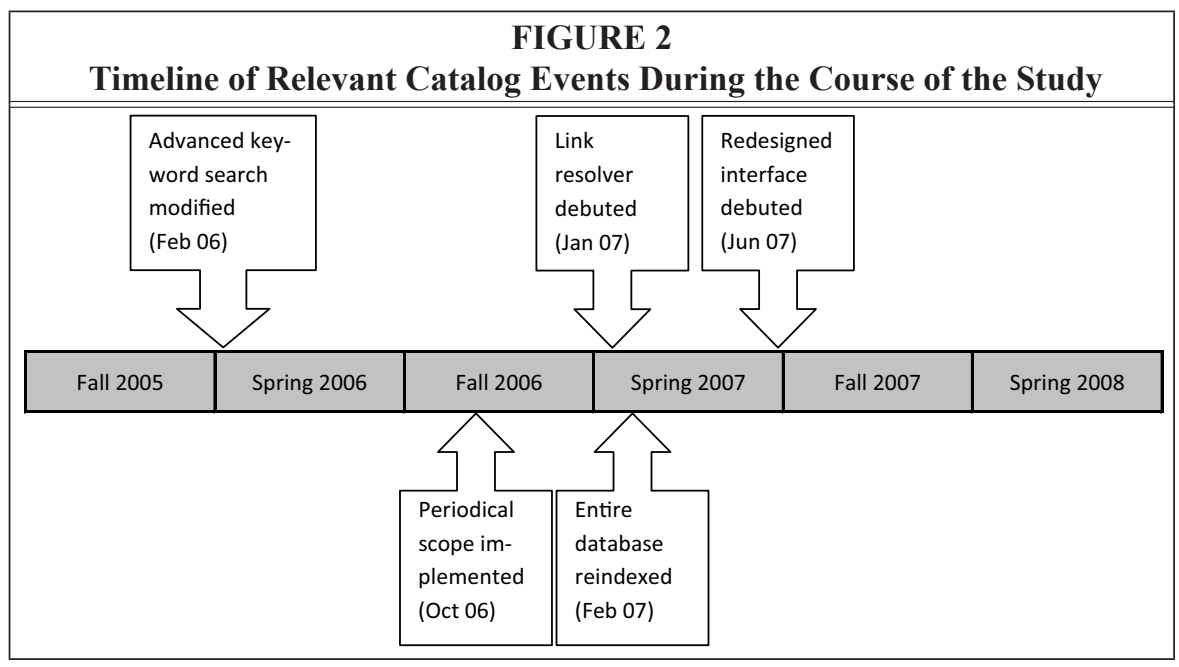

\section{Method}

\section{Data Collection}

A transactional log analysis was performed on the University of Colorado at Boulder's OPAC over the course of six semesters, ranging from fall 2005 through spring 2008. TLA is the only method that lends itself to a longitudinal analysis, allowing researchers to understand emerging patterns over the course of time as the library made improvements to the OPAC interface. Since this study relates to general trends of how the library catalog is being used rather than specific or individual usage, the authors believe TLA to be appropriate for this project, despite its aforementioned shortcomings.

\section{Catalog Events}

As noted, this study was conducted to capture the broad changes in user behavior trends before and after modifications to our OPAC. The largest modification came in June 2007 when the committee overhauled the OPAC with a complete redesign of the interface (see figures 1a and $1 \mathrm{~b}$ ). An influential element of this redesign was the decision to create a simple keyword search as the default search. Other changes over the course of the past few years consisted of the inclusion of an advanced keyword search in February 2006; a change to a periodical scope, instead of a periodical title search, in October 2006 (this change moved periodical title searches into the title search category instead of an independent category); the implementation of a link resolver, WebBridge, in mid-January 2007; and a re-indexing of the entire database in February 2007. A timeline of all these events is included above (see figure 2). Of all the modifications made to the functionality of the catalog, the authors determined that the introduction of the link resolver and the interface redesign appeared to trigger the largest changes in user behavior.

\section{Time Periods Selected for Analysis}

For each semester from fall 2005 to spring 2008, the authors chose three collection date ranges. The Public Services department of the University Libraries has a pre-established two-week sampling period that falls roughly between weeks ten and fourteen of every semester. Therefore, for each semester, the authors selected data that coincided with that two-week sampling period. To collect data from times that we hypothesized might have different use patterns, we also included data from weeks two and three of the semester, in addition to data from finals week. These three data collection periods were chosen to represent various stages 
of high-use and low-use times in the library to reach an average usage of the OPAC throughout the semester. The transactional log data from these representative periods between August 2005 and May 2008 amounted to a total of over 4.1 million patron queries. The authors were limited in important ways by the availability of data. Data were pulled from the integrated library system (ILS), Innovative Interfaces, Inc. in this case, and recorded on a semiregular basis.

However, the authors could not control the exact date ranges for which data were recorded. While many date ranges were seven-day periods, some were much longer. In particular, the time periods that included finals weeks tended to be of widely varying lengths, from seven to thirty-five days. The authors believed it important to include data from finals weeks and elected to incorporate these longer date ranges, while also attempting to compensate for the varying lengths through other means. When date ranges did not match the ideal dates for the study, the authors selected the date range that was closest to the time frame we were evaluating. See table 1 for exact dates.

The library began preparing for a major renovation in the spring of 2008. Part of these preparations included transferring large numbers of periodicals to storage during construction. During the time these periodicals were unavailable, patrons were directed to the link resolver to encourage them to search for the full
TABLE 1

Date Ranges for Analysis

\begin{tabular}{|l|l|c|}
\hline Time Period & Semester & $\begin{array}{c}\text { Number } \\
\text { of Days }\end{array}$ \\
\hline Weeks 2 and 3 & Fall 2005 & 34 \\
\hline Sampling Period & Fall 2005 & 14 \\
\hline Finals Week & Fall 2005 & 34 \\
\hline Week 2 & Spring 2006 & 7 \\
\hline Week 3 & Spring 2006 & 7 \\
\hline Sampling Period & Spring 2006 & 14 \\
\hline Finals Week & Spring 2006 & 7 \\
\hline Week 2 & Fall 2006 & 7 \\
\hline Week 3 & Fall 2006 & 8 \\
\hline Sampling Period & Fall 2006 & 14 \\
\hline Finals Week & Fall 2006 & 21 \\
\hline Week 2 & Spring 2007 & 7 \\
\hline Week 3 & Spring 2007 & 8 \\
\hline Sampling Period & Spring 2007 & 14 \\
\hline Finals Week & Spring 2007 & 21 \\
\hline Weeks 2 and 3 & Fall 2007 & 21 \\
\hline Sampling Period & Fall 2007 & 21 \\
\hline Finals Week & Fall 2007 & 31 \\
\hline Week 2 & Spring 2008 & 12 \\
\hline Week 3 & Spring 2008 & 7 \\
\hline Sampling Period & Spring 2008 & 14 \\
\hline Finals Week & Spring 2008 & 7 \\
\hline
\end{tabular}

text of the periodicals before ordering the items from interlibrary loan. The authors hypothesized that this could influence the number of searches initiated by the link resolver. Though these data may display the influences of the renovation project in addition to catalog design, the authors believe that the data are still relevant indicators of user behavior, and they elected to include the data from the spring 2008 finals week.

Data from the study can be broken down and compared in several different ways: Weeks 2 and 3 (a sum of both), Sampling Periods, Finals Week, Fall Semesters, Spring Semesters, and All Dates Combined. Depending on the date ranges 
and comparisons one chooses, different impressions of catalog use emerge. Breaking data into smaller groups can offer interesting insights that might be obscured when looking at all dates combined.

There exist multiple methods of evaluating the data: actual number of searches, percentage of total searches, and a daily average of searches. Each method paints a different picture of catalog use. Since data did not allow for date ranges to be exactly the same length, actual number of searches may be a misleading number. Since some "finals week" data periods, for reasons beyond the control of the authors, are very long while others are rather short, the higher numbers of searches in the longer time periods may inadvertently skew the data in favor of that semester. To ameliorate this weakness of the data, there are two ways to control for the different time periods. One method is to express the data as a daily average by dividing the number of searches by the number of days in the sample. Another method is to express the data as a percentage of the total number of searches from that same time period. One major weakness of the daily average approach is that it does not correct for unusually slow periods that might be in the study. For example, one data set begins in finals week and ends right after New Year's. The stretch of days between the end of finals and New Year's Eve is the slowest of the year, especially since the library is closed for much of that time. Other data sets from the same time period in other years tend to go much longer into January, some even into the first week of the spring semester. Thus, while the other date ranges include the very slow period, they also include busier time periods that the shorter data set lacks. As a result, usage for the semester in which the data ends early appears to be very low when studied as a daily average. However, when evaluated as a percentage of total searches, the marked drop in use disappears, suggesting that usage of the different kinds of searches did not decline in a significant way during that particular time period. Because of this substantial weakness of evaluating the data based on daily averages, the authors agreed that evaluating searches as a percentage of the total searches would create the most accurate reflection of catalog use.

\section{Kinds of Searches}

As with most integrated library systems, the data available are larger than one study can encompass. This study will focus particularly on transaction data regarding query type or index use. Query type reports the number of searches in: keyword, title, author, Library of Congress (LC) call number, subject, government document number, ISNs, local call numbers, record numbers, Dewey call numbers, OCLC numbers, Prof/TA, Course, and Periodical Title, in addition to several others. More specifically, this study will focus on three general areas of data, evaluating three kinds of searching behavior. First, this study will investigate four kinds of text searches: keyword, title, author, and subject. Second, this paper will study two kinds of number searches: LC call number and ISSN/ISBN. Government document call number searches, Dewey call number searches (the University of Colorado at Boulder primarily uses an LC call number system), and local call number searches do not represent large enough numbers to be usefully evaluated when compared with the other numbers, so those data are not evaluated here. The data show high numbers of OCLC number searches. However, since the Access Services (e.g., Interlibrary Loan) and Acquisitions departments perform a great deal of OCLC number searches, the authors believe that this particular number is an indication not of patron searching behavior but of librarian/library staff searching behavior, which is beyond the scope of this study. Third, this study will review total catalog searches. For one data set, finals week 2005, the query type/index data were pulled but not recorded and so could not be included in the study. 


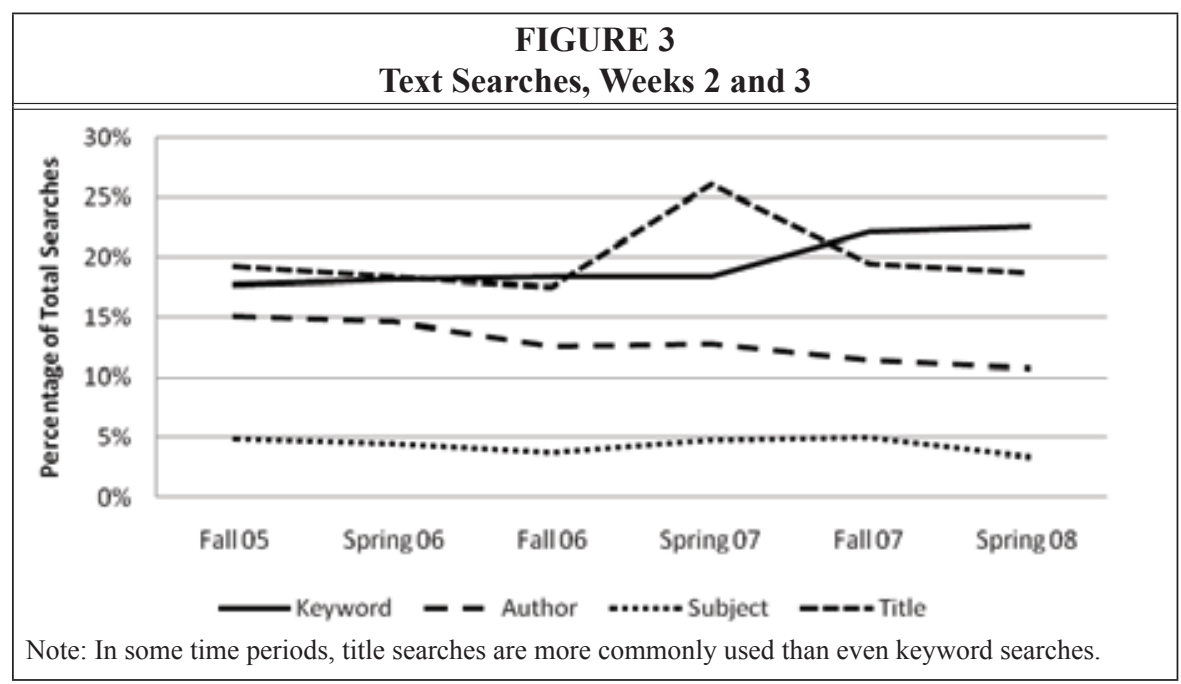

The data in the transactional logs for each category were entered into a spreadsheet to analyze the trends over time. Finally, statistics were calculated and a T-test was run to determine if there was a statistically significant difference between user behavior before and after each of the two major changes to the OPAC. T-tests were also used to compare the different time periods selected for analysis over the course of time.

\section{Results and Discussion Text Searches \\ Title Searches}

Title searches were more popular than the authors expected (see figure 3). Particularly in finals weeks, and to a lesser extent during weeks two and three of the semester, title searches were more popular than keyword searches. By contrast, keyword searches far outweighed title searches during sampling weeks. T-test results that compared keyword searches during weeks two and three versus the sampling weeks, and then user searches during finals week and sampling weeks, had P-values of 0.000001 and 0.0002, respectively. Therefore, there is a statistically significant difference at the 0.01 level between the keyword searches that users conduct throughout the semester.
The analysis of these statistical values indicates that at the beginning and end of the semester, users are more likely to be searching for known items than in the middle of the semester, when perhaps catalog use is more dominated by patrons using the catalog to discover unknown resources. The authors found this particular result to be surprising, since we did not realize that so many patrons search for known items at the beginning and end of the semester. This result perhaps raises the question of whether a keyword search default is appropriate during the first and last few weeks of the semester, when title searches dominate user search choice. The argument could be made that the value of interface consistency outweighs this pattern of usage, but it certainly could be an element for discussion. The overall use of title searches increased substantially in the fall of 2006 (see figure 4). This rise in the use of title search coincides with the introduction of a periodical title scope, which moved statistics of periodical title searches into the title index. Before that time, periodical title searches were recorded in a separate index just for periodical titles. The rise in title searches once the two indexes were combined suggests that periodical title searches may be responsible for a large 


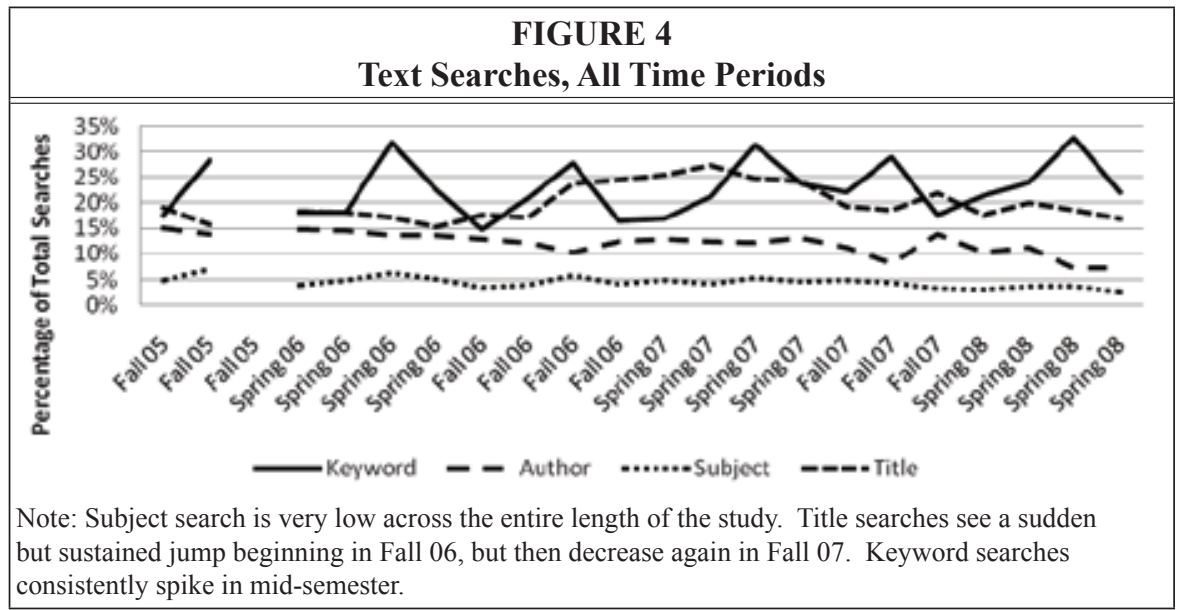

number of title searches performed in the catalog. This supports anecdotal evidence that a large percentage of users employ the library catalog primarily to identify journal literature. One might expect that these users are likely to be concentrated in disciplines whose publishing outputs are primarily articles rather than books. Interestingly, when the new interface was introduced, the percentage of title searches changed again - the percentage of title searches fell. The new interface defaults to a keyword search, perhaps indicating that patrons do not necessarily take the time to change their search types away from the default of keyword, even when they are looking for known items. It would be interesting to discover whether users are equally successful at locating their desired items when using the default keyword search as they are when using a title search. Since our data do not include information about user success, this would require a separate study.

\section{Subject Searches}

Subject searches are consistently lower than keyword, title, or author. Librarians have long believed that subject search is the best access to library holdings. How-

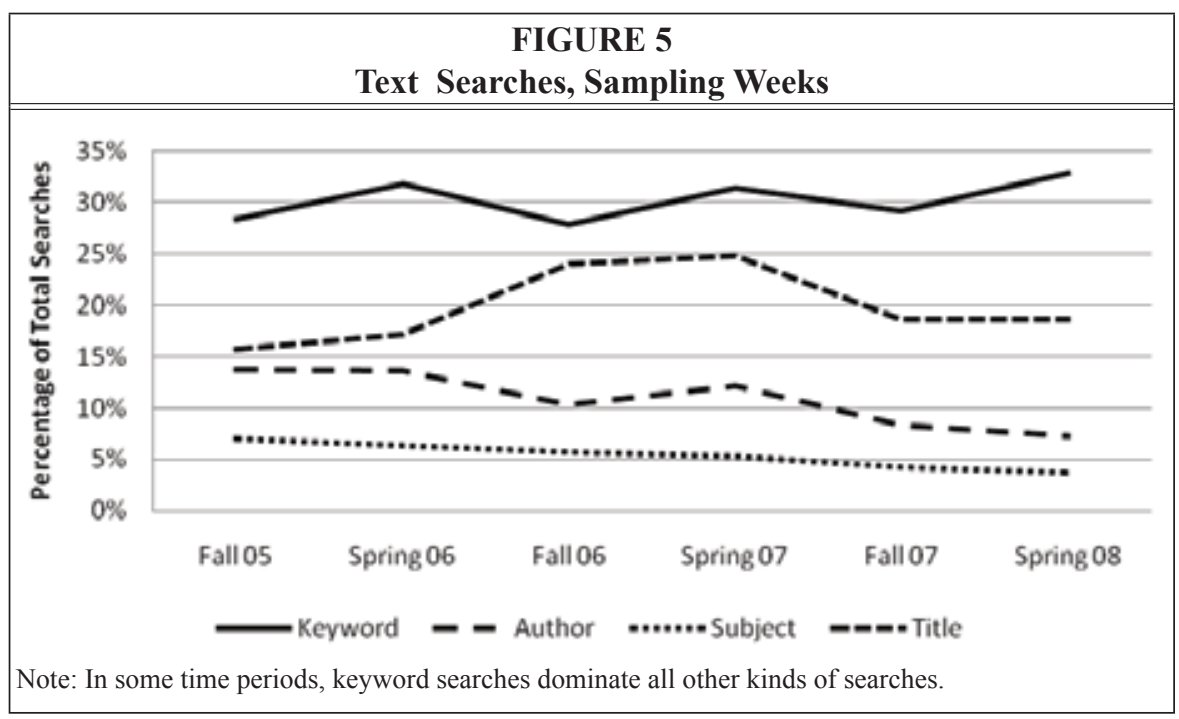


ever, it is rarely used. The difficulties users experience with subject searching have been reported by many researchers, most prominently by Larson in his longitudinal study over a six-year period. ${ }^{14}$ A more recent article finds that "user success in subject searching remains problematic."15 In this University of Colorado at Boulder study, subject searches were consistently lower than keyword, title, or author. This finding was supported by a T-test that was run to determine the statistical significance of user searches before versus after the catalog redesign. Specifically, the usage of the subject search decreased from nearly 5 percent of searches down to 3.69 percent of searches; this decrease had a P-value of 0.0106 , indicating a statistically significant difference at the 0.05 level. It is conceivable that subject searches may be lower in the years since library users have become accustomed to Internet search engines, where subject searching is not available. In addition, it is likely that subject searches are rarely chosen because successful use of subject searches requires at least some rudimentary knowledge of structured subject headings - a knowledge that is quite rare in patrons since the demise of the card catalog. Regardless of the reasons that subject searches are rarely chosen by patrons, interface and catalog design should recognize and accommodate both the low usage of subject search and the high usage of keyword and title search. Designing a catalog to encourage use of subject searches may be more likely to frustrate and deter users who prefer keyword and title searches, rather than to encourage them to learn to use subject searching.

\section{Keyword Searches}

Keyword searches are the most mysterious and unexpected of the statistics tracked. Sometimes keyword searches far outweigh title searches (see figure 5). This dominance of keyword search matched the authors' expectations of catalog use. This dominance is consistently apparent during sampling weeks, as previously noted with the T-test results, suggesting that, in the middle of the semester, users are more likely to be engaging in discovery of unknown resources than during other periods of the semester.

In a surprising contrast, however, at other times keyword searches barely compete or are even outstripped by title searches (see figure 6). In the beginnings and ends of semesters, usage of keyword searches decreases, sometimes dipping

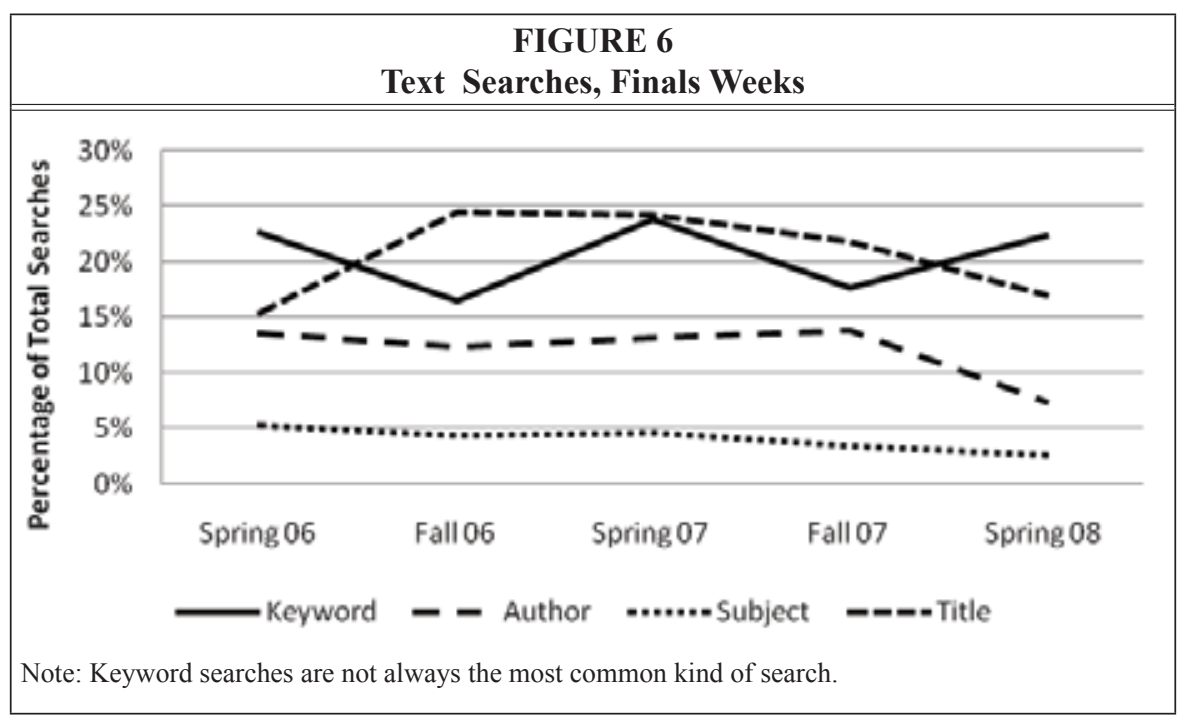


below title search. However, in the spring of 2008, the last semester studied, keyword searches rose above title searches, which marked a change in earlier trends. More study is necessary to determine if this jump in keyword searches in spring of 2008 is an ongoing trend or just a onetime occurrence. If it turns out to be a trend, then the redesign of the catalog seems to be the most likely source of the increase. In the middle of semesters, usage of keyword searches is much higher than earlier and later in the semesters, and is consistently the most used search for that time period (see figure 4). What seems to be most consistent is that use of keyword search is cyclical, routinely spiking in midsemester.

\section{Author Searches}

At the beginning of the study, author searches were nearly as common as title searches, but author searches have steadily declined in popularity. The decline in author searches was confirmed by our T-test results, which compared author searches before and after the catalog redesign and showed a P-value of 0.0007, indicating a statistically significant difference at the 0.01 level. An author search is less intuitive than a keyword or title search, since one must input the author's last name first. This is particularly counterintuitive in comparison to Internet search engines and many subscription article databases, both of which perform more successful searches when authors' names are typed first name first. It is conceivable that this conflict is partly responsible for the decreasing use of author search. It is also possible that more users are simply using the keyword search to find authors, since keyword is the default and is often still successful at retrieving relevant sources using names.

Of all the text searches, keyword and title searches seem to demonstrate the clearest long-term trend. Both searches tended to increase over the course of the entire study. Subject searches are somewhat less used at the end of the study than at the beginning. Only author searches show a steady decline. These four kinds of searches represent the most popular searches performed in the catalog. It is not surprising that patrons prefer these text searches, since these are typically the most intuitive search types, as well as the most memorable identifiers of a book (as opposed to an ISBN or call number, for example).

\section{Number Searches \\ ISBN/ISSN Searches}

The most interesting result of the number searches is the increase in ISSN/ ISBN searches. The authors were quite surprised to see an increase in ISBN/ ISSN searches early in fall of 2006, a full semester before implementation of the link resolver. One potential explanation for this unpredicted rise is the implementation of a periodical scope that semester. Before the periodical scope, an easy option existed to search for periodicals by title but not by other elements. It was extremely difficult to locate the ISBN/ISSN search; to search by a standard number, users would have to choose "Call Number" search and then "Other Number" search, and finally "ISBN/ISSN/Standard Number" search. This counterintuitive path to an ISBN/ISSN search impeded users who may have wished to search by standard number. After the introduction of the periodical scope, it was simpler to search for periodicals by ISSN. In addition, it was a great deal easier to locate this search option. The authors believe that the increased ease with which users could locate a standard number search could account for the initial rise in ISSN/ ISBN searches. In addition, ISBN/ISSN searches rose substantially in spring of 2007 when compared with the previous spring (see figure 7). This is most likely the result of the implementation of a link resolver. To confirm that the increase in ISBN/ISSN searches was indeed a result of the debut of the link resolver and not the catalog redesign, the authors conducted two additional T-tests. First, we compared 


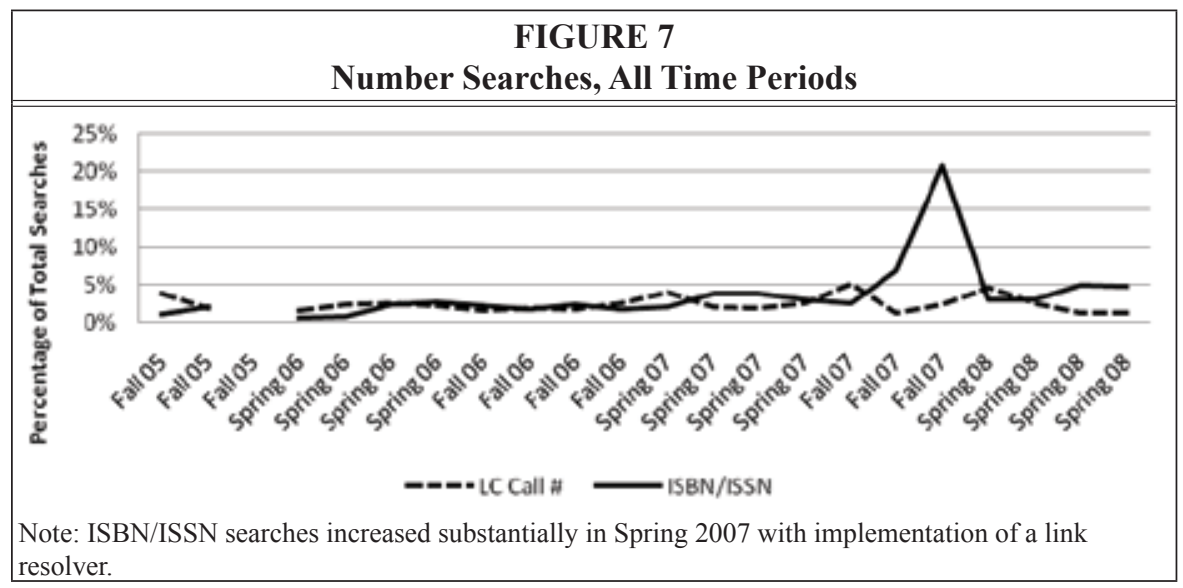

the ISBN/ISSN searches before and after the link resolver was implemented. This showed a P-value of 0.0491 , indicating a statistical significance at the 0.05 level. Then we ran a T-test comparing the ISBN/ISSN usage after the link resolver implementation but before the catalog redesign, which resulted in a P-value of 0.3251 , showing no significant difference between the ISBN/ISSN usage in those time frames. This supports the authors' conjecture that the difference in ISBN/ ISSN usage is related to the implementation of the link resolver, rather than the catalog redesign. However, there was a dramatic increase in usage of ISBN/ISSN searches in the fall of 2007, much higher than spring of 2007 when the link resolver was introduced. Possible explanations for this stunning rise are that more users were aware of the availability and purpose of the link resolver in the fall, a semester after it was first introduced; the redesign of the interface made it far easier to initiate an ISSN/ISBN search than it was previously; or that the resolver is becoming increasingly popular as students understand what it can do. Surprisingly, ISBN/ISSN searches dropped back down to a much lower level at the beginning of the spring 2008 semester.

\section{Library of Congress Call Number Searches} Another interesting element of number searches is the rise in Library of Congress call number searches. While it's true that, compared with most other kinds of searches, LC call number searches are somewhat less common, it remains interesting to note that LC call number searches rose dramatically during weeks two and three of the spring 2007 semester and peaked again during weeks two and three of fall 2007 and spring 2008 (see figure 7). During the remainder of the semesters, LC call number searches were low. T-test results that compared the different time periods selected for analysis show a statistically significant difference at the 0.10 level between the way users search with LC call numbers during weeks two and three versus the sampling weeks. This supports the idea that weeks two and three of the semester are more dominated than other weeks by known-item searching. Additionally, it supports the hypothesis that the redesigned interface allows a much simpler, more intuitive path to the LC call number search option than the previous interface.

Of the two kinds of number searches, ISBN/ISSN obviously shows the most dramatic increases in searches over time. LC call number searches do not show a clear trend over time either up or down; they seem to be holding steady as time passes. The authors suspect that usage of the ISBN/ISSN searches in particular will continue to rise, as users become more familiar with the link resolver and how to 
use it, and as the library creates paths for the link resolver in additional locations, such as online search engine results from computers on campus.

\section{Total Searches}

Also of interest to this study is the trend over time in total searches of any kind. Trend lines in sampling periods, finals weeks, fall semesters, spring semesters, and all time periods either hold steady or show steady increases over the course of the study in a number of searches (see figure 8). Many have been arguing in recent years that the library catalog is dead, that users favor online search engines to the extent that they simply do not use library catalogs. ${ }^{16}$ Their arguments suggest that catalog use will slowly dwindle to nothing, calling into question the value of not only catalog interface design and usability but, in effect, cataloging as a field and bibliographic control as a philosophy. If these arguments are accurate, then studies should demonstrate decreasing usage over time as users more and more consistently choose Internet search engines over the catalog, and especially as students entering universities are more accustomed to online searching and increasingly likely to turn there. This study suggests that these theories of the demise of the catalog are, at the very least, premature. This study shows not a decrease in catalog use over time, but an increase in most time periods. Particularly, catalog use is increasing in keyword, title, and ISSN searches (mostly via article databases). This indicates a possibility that users continue to turn to the library catalog, but perhaps they are searching it differently, relying more heavily on keywords and titles, as they would in an online search engine, than on more sophisticated searches like author and subject, or specifically library-related searches like call number. If libraries want their catalogs to remain relevant to users, it is important that catalog designs change over time to reflect the way that users are comfortable using the systems. Most of the major ILS vendors are currently in the early stages of development for just such "next generation discovery tools." It remains to be seen if these developmental products will draw catalog users and truly simplify resource discovery.

\section{Conclusion}

This study sought to investigate whether catalog interface design had a measurable influence on user search choice in several different kinds of searches including keyword, title, author, subject, ISN, and LC call number. Additionally, the authors were seeking evidence that catalog use was either declining or increasing over time. The authors collected data from the local integrated library system search log over the course of three years, or six semes-

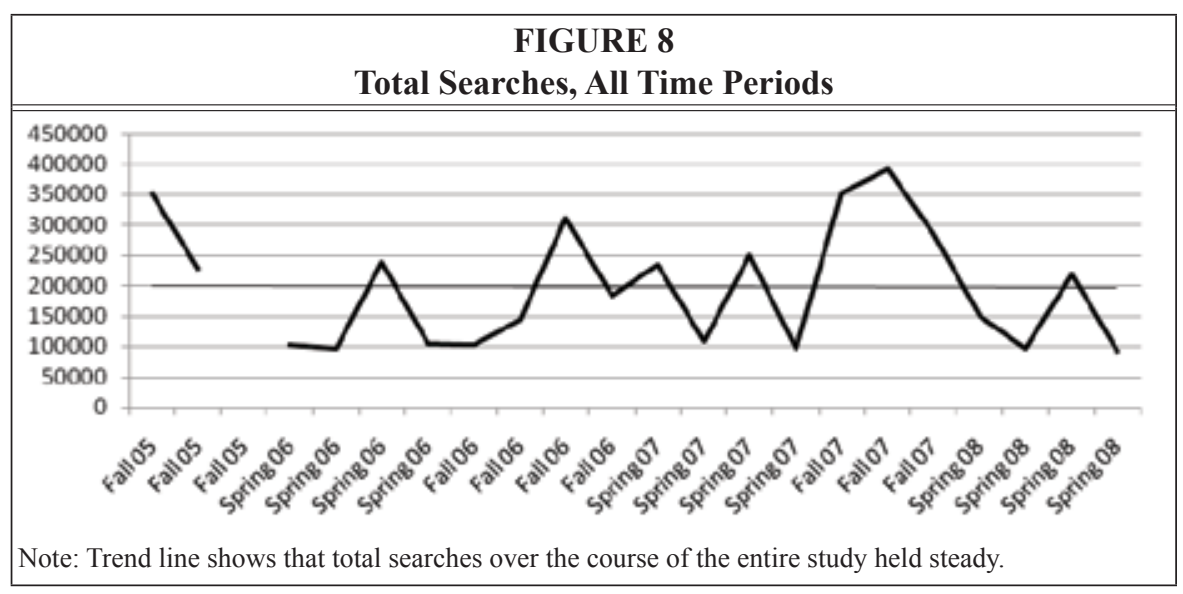


ters. The data demonstrate an increase in the number of keyword and ISBN/ISSN searches following implementation of the redesigned interface. The data also suggest that the implementation of a link resolver was highly influential, as searches initiated by the resolver created a large increase in catalog searches, particularly ISSN searches. Keyword search was the most prevalent search type in the middle of the semesters, while title search, surprisingly, was the dominant search both early and late in the semester. The authors found that overall catalog use is holding steady, in contrast to theories that catalogs are going unused by patrons who prefer other online search engines. This research supports the notion that catalog interface design, and indeed cataloging itself, remain worthwhile practices for libraries. The authors suggest that further, qualitative study of user search behavior would be beneficial to understanding the influence of modern interface design on search behavior.

\section{Notes}

1. Andrew Large and Jamshid Beheshti, “OPACs: A Research Review," Library E Information Science Research, 19, no. 2 (1997), 111-33.

2. David Meister and Dennis J. Sullivan, "Evaluation of User Reactions to a Prototype On-Line Information Retrieval System," Report to NASA by the Bunker-Ramo Corporation. Report Number NASA CR-918 (1967).

3. Thomas A. Peters, "The History and Development of Transaction Log Analysis," Library Hi Tech 11, no. 2 (1993), 41-66.

4. B. Sandore, "Applying the Results of Transaction Log Analysis," Library Hi Tech 11, no. 2 (1993), 87-97.

5. Martin Kurth, "The Limits and Limitations of Transaction Log Analysis," Library Hi Tech 11, no. 2 (1993), 98-104.

6. Ibid., 99.

7. Rhonda N. Hunter, "Successes and Failures of Patrons Searching the Online Catalog at a Large Academic Library: A Transaction Log Analysis," RQ 30, no. 3 (1991), 395; Ray R. Larson, "The Decline of Subject Searching: Long-Term Trends and Patterns of Index Use in an Online Catalog," Journal of the American Society for Information Science 42, no. 3 (Apr. 1991), 197-215; Diane Vizine-Goetz and Karen Markey Drabenstott, "Computer and Manual Analysis of Subject Terms Entered by Online Catalog Users," Proceedings of the ASIS Annual Meeting 28 (1991), 156-61; N.S. Bangalore, "Re-Engineering the OPAC Using Transaction Logs," Libri: International Journal of Libraries and Information Services 47, no. 2 (1997), 67-76; Deborah D. Blecic and others, "Using Transction Log Analysis to Improve OPAC Retrieval Results," College E Research Libraries 59, no. 1 (1998), 39; Deborah D. Blecic and others, "A Longitudinal Study of the Effects of OPAC Screen Changes on Searching Behavior and Searcher," College E Research Libraries 60, no. 6 (1999), 515 (to name a few).

8. Eric Novotny, "I Don't Think I Click: A Protocol Analysis Study of Use of a Library Online Catalog in the Internet Age," College E Research Libraries 65, no. 6 (2004), 525-37.

9. Holly Yu and Margo Young, "The Impact of Web Search Engines on Subject Searching in OPAC," Information Technology E Libraries 23, no. 4 (2004), 168-80.

10. Luis Villen-Rueda, Jose A. Senso, and Felix De Moya-Anegon, "The Use of OPAC in a Large Academic Library: A Transactional Log Analysis Study of Subject Searching," Journal of Academic Librarianship 33, no. 3 (2007), 327.

11. M. Hancock-Beaulieu, "Evaluating the Impact of an Online Library Catalog on Subject Searching Behavior at the Catalog and at the Shelves," Journal of Documentation 46, no. 4 (1990), 318-38; Barbara M. Wildemuth and Ann L. O'Neill, “The 'Known' in Known-Item Searches: Empirical Support for User-Centered Design," College E Research Libraries 56, no. 3 (1995), 265.

12. Aphrodite Malliari and Daphne Kyriaki-Manessi, "Users' Behaviour Patterns in Academic Libraries' OPACs: A Multivariate Statistical Analysis," New Library World 108, no. 3/4 (2007), 107.

13. Peters, "The History and Development of Transaction Log Analysis."

14. Larson, "The Decline of Subject Searching."

15. Yu and Young, "The Impact of Web Search Engines on Subject Searching in OPAC," 168.

16. One of many examples is Deanna B. Marcum, "The Future of Cataloging," Library Resources $\mathcal{E}$ Technical Services 50, no. 1 (2006), 5-9. 


\section{“An investment in knowledge pays the best interest." \\ - Benjamin Franklin}

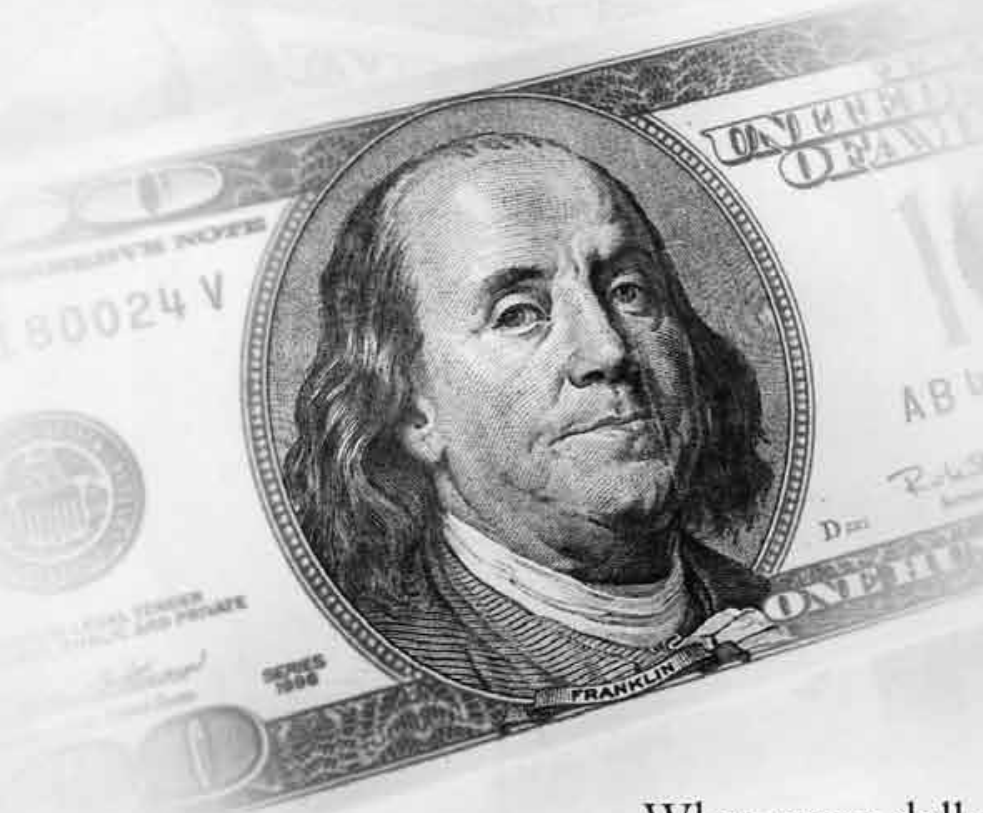

When every dollar counts, get the most out of your budget with Choice Reviews Online.

The perfect companion to a CHOICE print subscription:

- Access to over 145,000 CHOICE reviews

- Download, print or e-mail search results

- Ability to create a customized profile

- Create, save and e-mail lists

- Search all CHOICE content

- View exclusive online material

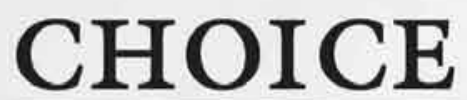

R E V I E W S O N L I N E

To learn more about Choice Reviews Online, visit us at www.cro2info.org or sign up for a free 60-day trial at www.cro2.org

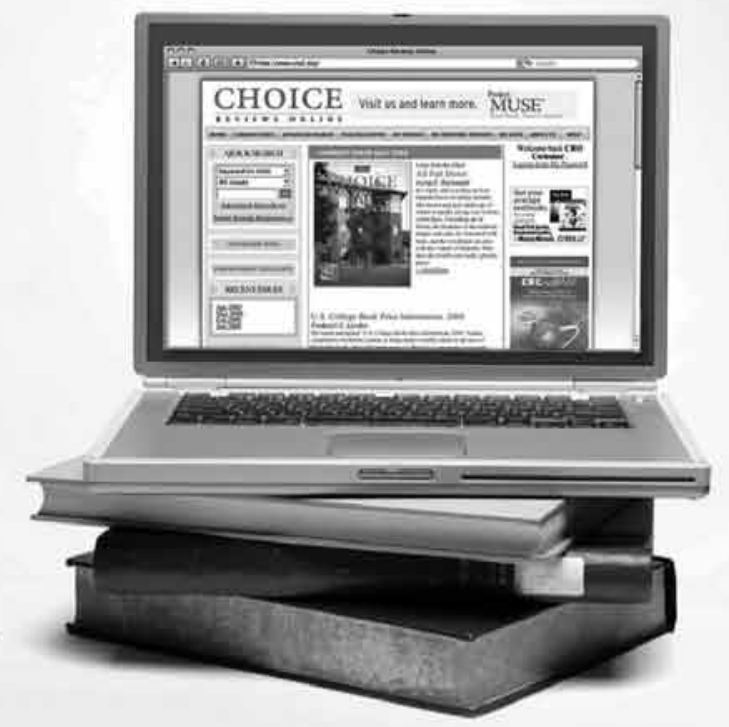

